技術論文

지상관측법 및 $\mathrm{DGPS}$ 기법을 활용한 이/착륙 성능 비행시험 비교

이상종*, 장재원*, 전병호*, 성기정*, 염찬홍**

\title{
Comparison Study on Take-Off and Landing Flight Test Using Ground Observation and DGPS Method
}

Sangjong Lee*, Jae-Won Chang*, Byoung-Ho Jeon*, Kiej-Jeong Seong* and Chan-Hong Yeom**

\begin{abstract}
The flight test is last means of compliance to satisfy airworthiness standards and important to evaluate the performance and safety of the developed aircraft. The flight test technologies are obtatined from great numbers of experiences and know-hows and protected. In addition, flight test should be conducted efficiently since its various test conditions and items. Therefore, it is requisite to secure efficient flight test methods. This paper discusses the flight test methods for take-off and landing performance and two kinds of techniques are propesed. By performing real flight tests, they are compared with each other and analyzed through the flight analysis.

\section{초 록}

비행시험은 개발 항공기의 다양한 성능검증을 포함하여 감항기술기준에 대한 안전성을 입증하는 최종시험으로서 중요성이 크다. 특히, 민간 항공기의 비행시험은 개발업체의 경 험 및 노하우에 의해 기술 보호성격이 강하며, 다양한 시험항목과 비행조건에 의해 비용 이나 시간측면에서 효율적인 비행시험 수행 및 비행시험 기법의 확보는 필수적이다. 본 논문에서는 이륙 및 착륙성능 입증을 위한 이착륙 비행시험에 대해 지상관측법과 DGPS를 활용한 비행시험 기법을 제안하고 실제 비행시험을 수행하여 그 결과를 비교하였다.
\end{abstract}

Key Words : Flight Test(비행시험), Certification(인증), Take-off Performance(이륙 성능), Landing Performance(착륙 성능), Telemetry(텔레메트리)

\section{I. 서 론}

항공기의 개발과정은 항공기 설계 과정과 시 제기 제작 과정, 그리고 개발 항공기에 대한 시 험평가로 크게 구분된다. 민간 항공기의 경우 안 전을 최우선적으로 고려하기 때문에 이를 검증하 기 위한 시험평가가 매우 중요하며, 새로운 소재

† 2009년 5월 15일 접수 2009년 8월 21일 심사완료

* 정회원, 한국항공우주연구원 항행·제어팀

교신저자, E-mail : albert@kari.re.kr

대전광역시 유성구 과학로 115 번지

** 정회원, 한국항공우주연구원 항공기술실
및 첨단 디지털 전자장비의 사용 및 제작 공정의 발전으로 인하여 개발 항공기의 안전을 입증하기 위해 시험평가에 대한 중요도가 증가하고 있는 추세이다. 이러한 항공기 시험평가는 크게 지상 시험과 비행시험으로 분류할 수 있으며, 비행시 험은 지상시험에서 수행할 수 없는 항목들에 대 한 시험뿐 아니라 다양한 분야에 대한 안전성 입 증과 운용자료 취득을 위해 수행된다. 민간항공 기의 운항에 따른 안전성 확보를 위해 설계·제 작(생산) · 운용 등의 모든 과정에서 안전성 요구 사항에 대한 적합성을 기술적으로 판단하고, 이 에 따른 승인 - 허가·제한 - 금지 등의 법적 처분 을 하는 일련의 행위를 『항공기 인증 (Aircraft 


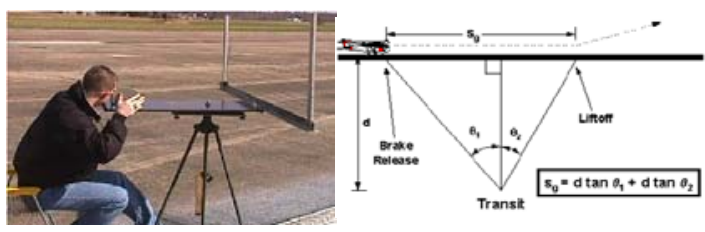

Fig. 1. Classical ground observation method

Certification)』이라 정의하며, 국제민간항공기구 (ICAO)는 항공기 및 승객의 안전을 확보하기 위 해 시카고 협약 제 31 조에 의해 항공기 인증을 국가의 의무사항으로 규정하고 있다[1]. 현재 국 내 항공기 기술기준은 미연방항공청의 기술기준 (14 CFR, Code of Federal Regulations)을 바탕 으로 항공기 기술기준을 규정하여 사용하고 있으 며, 항공기 형식증명을 위해서는 기술기준 각 항 목에 대한 설계 적합성을 입증하여야 한다[2]. 결 국 인증 측면에서 비행시험은 개발 항공기가 각 해당 기술기준을 만족함을 입증하기 위한 최종 적합성 입증방안 (MOC, Means Of Compliance) 으로 활용되며, 감항당국의 최종적인 안전성 판단요소 로 작용한다.

본 논문에서는 수많은 비행시험 항목 중 KAS Part 23의 적용을 받는 소형 항공기의 이륙과 착 륙 성능을 도출하기 위한 비행시험 기법과 실제 비행시험 수행 결과를 고찰하였다. 항공기의 이륙 및 착륙 성능은 이륙/착륙거리와 항공기의 속도 를 측정하여 평가하게 되는데, 기존의 비행시험에 서는 지상 관측자가 Fig. 1에서와 같이 눈금선이 그려진 장비를 이용하거나 비디오 장비를 이용하여 이륙 및 착륙거리를 측정하는 방법을 사용하였다.

이러한 기존 방법은 거리 측정은 가능하나 항 공기의 속도 측정은 불가능하며, 특히 측정오차 를 크게 포함하고 있어 정확한 성능 자료를 제공 하기 어렵다는 단점을 가지고 있다. 본 논문에서 는 이러한 단점을 극복하고 보다 정확한 성능 자 료를 결정하기 위해 최신 기술을 활용한 두 종류 의 이착륙 비행시험 기법을 제안하고, 실제 비행 시험에서 이를 활용하여 획득한 데이터의 분석을 통해 두 기법의 장단점을 비교하고 제시하였다.

\section{II. 이착륙 관련 감항 기술기준}

$\mathrm{ICAO}$ 가입국인 우리나라도 항공법 제 15 조 5 항에서 민간항공기의 안전한 운행을 확보하기 위 해 기술상의 기준을 제정토록 규정하고 있으며, 현재 국내에서는 “항공기 기술기준 (KAS, Korea Airworthiness Standard)"이 제정되어 고시하고
Table 1. Airworthiness standards related with take-off and landing

\begin{tabular}{|c|l|}
\hline 항 목 & \multicolumn{1}{|c|}{ 내 용 } \\
\hline$\S 23.51$ & Takeoff speeds \\
\hline$\S 23.53$ & Takeoff performance \\
\hline$\S 23.55$ & Accelerate-stop distance \\
\hline$\S 23.57$ & Takeoff path \\
\hline$\S 23.59$ & Takeoff distance and takeoff run \\
\hline$\S 23.61$ & Takeoff flight path \\
\hline$\S 23.73$ & Reference landing approach speed \\
\hline$\S 23.75$ & Landing distance \\
\hline$\S 23.77$ & Balked landing \\
\hline
\end{tabular}

있다[2]. 소형 항공기는 Part23의 기준에 의거하 여 최대이륙중량 $12,500 \mathrm{lbs} /$ 승객수 10 인승 이하 의 항공기이거나, $19,000 \mathrm{lbs}$ 이하/승객수 19 인승 이하의 프로펠러로 구동되는 커뮤터 (commuter) 급 항공기로 정의된다. Part 23 감항기술기준은 Subpart A G까지 총 7개로 분류되어 있으며 이 륙 및 착륙에 해당하는 감항기술기준은 Table 1 과 같다[2][3]. 이 중 \$23.55 61 기준은 커뮤터급 항공기에 적용되는 기준으로 본 논문에서 대상으 로 하는 Test-bed 항공기의 종류에 해당되지 않 아 적용하지 않는다.

\section{III. 이륙 및 착륙 관련식}

\section{1 이륙비행단계 구분 및 보정식}

이륙 비행시험의 주요한 목적은 안전한 이륙 을 위해 필요한 모든 기동을 충분히 보장하는 속 도와 고도를 얻을 수 있는 항공기의 이륙거리를 정의하는 것이 첫 번째이며, 커뮤터나 다발 항공 기 (multi-engine airplane)의 경우는 단발 항공기 에 비해 보다 상세한 속도 및 고도, 이륙경로 등 이 결정되어져야 한다. 이륙성능은 $\$ 23.53$ 항에 의 거 이륙거리를 사용하여 성능이 결정되는데, 이 륙거리는 Fig. 2와 같이 항공기 앞바퀴가 활주로 면 위에서 떨어지고 뒷바퀴는 활주로면에 닿아있 는 부양 (lift-off) 단계까지의 지상이륙활주거리 (take- off ground roll distance, $S_{1}$ )와 가상적인 장애물 고도 (obstacle height)까지의 공중이륙거 리 (take-off air phase distance, $S_{2}$ )로 이루어진 다. Part 23의 장애물 고도는 $50 \mathrm{ft}(15 \mathrm{~m})$ 를 정 의하고 있다[2][3].

이륙 비행 중 항공기에는 추력 $(\mathrm{T})$, 양력 $(\mathrm{L})$, 무게 $(\mathrm{W})$, 항력 $(\mathrm{D})$ 및 지상 마찰력 $(\mathrm{R})$ 이 작용 하며, 에너지 보존법칙을 적용하면 다음 식 (1)과 (2)를 적분하여 이륙거리를 구할 수 있다. 


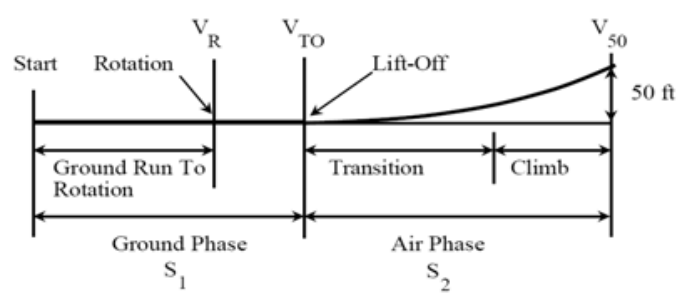

Fig. 2. Take-off Phase

$$
\begin{aligned}
& \int_{0}^{S_{1}}[T-D-\mu \cdot(W-L)] d S=\frac{1}{2} \frac{W}{g}\left(V_{T O}^{2}\right) \\
& \int_{S_{1}}^{50 f t}(T-D) d S=\frac{1}{2} \frac{W}{g}\left(V_{50}^{2}-V_{T O}^{2}\right)+50 W
\end{aligned}
$$

임의 구간에서의 평균값을 사용하면 다음 식 (3) 과 (4)로 유도되는 지상 및 공중 이륙거리를 구 할 수 있다.

$$
\begin{aligned}
S_{1} & =\frac{W \cdot V_{T O}^{2}}{2 g[T-D-\mu(W-L)]_{A v g}}=\frac{W \cdot V_{L O F_{g}}^{2}}{2 g \cdot T_{e x_{A y g_{e}}}} \\
S_{2} & =\frac{W \cdot\left(\frac{V_{50}^{2}-V_{T O}^{2}}{2 g}+50\right)}{(T-D)_{A v g}}
\end{aligned}
$$

여기서, $V_{T O}, V_{50}$ 는 이륙 부양속도 및 $50 \mathrm{ft}$ 장애 물 고도에서의 속도를 나타낸다. 식 (3)과 (4)로 구해진 이륙거리는 시험당일의 바람조건 및 활주 로 기울기와 추력, 무게 및 밀도변화를 보상하여 표준조건에서의 거리로 보정하여야 한다[4].

\subsection{1 바람속도 보정 (Wind Correction)}

이륙활주 중 lift-off시의 대지속도 (ground speed) $V_{L_{O F}}$ 는 아래와 같이 항공기의 진대기 속 도 (true airspeed) $V_{L O F_{a}}$ 와 바람속도 (wind speed) $V_{w}$ 의 벡터합으로 표현된다.

$$
\mathrm{V}_{L O F_{g}}=\mathrm{V}_{L O F_{a}}+\mathrm{V}_{w}
$$

따라서 식 (5)을 식 (3)에 대입하면 바람속도가 보정된 지상 활주이륙거리를 구할 수 있으며, 바 람이 있는 경우 측정된 대지속도와 실제 이륙거 리에 대한 보정식은 식 (6)과 같이 정의된다.

$$
S_{1_{\text {sdd }}}=S_{1} \cdot\left(1+\frac{V_{w}}{V_{L_{\text {OF }}}}\right)^{1.85}
$$

\subsection{2 활주로 기울기 보정(Runway Slope Correction)}

활주로에 기울기가 있을 경우는 이륙시 운동 에너지에서 경사로 인해 생기는 위치에너지 $W \cdot S_{1_{\mathcal{L}}} \cdot \sin \Phi$ ( $\Phi$ 는 활주로 기울기)를 빼주면 식
(7)로 유도되는 총일의 양을 구할 수 있고 (바람 속도를 먼저 보정하는 경우, $S_{1_{\text {std }}}=S_{1_{\text {SLL }}}$ 이 됨),

$$
T_{e x_{\text {Ay }}} \cdot S_{1_{S L}}=\frac{1}{2} \frac{W}{g} V_{L O F_{g}}^{2}-W \cdot S_{1_{S L}} \cdot \sin \Phi
$$

윗 식을 $T_{e x x_{x y}}$ 에 대해서 정리한 후 식 (3)에 대입 하면 다음과 같은 보정식을 유도할 수 있다.

$$
S_{1_{s t d}}=\frac{S_{1_{S L}}}{\left(1-\frac{2 g \cdot S_{1_{S L}}}{V_{L O F_{g}}^{2}} \cdot \sin \Phi\right)}
$$

\subsection{3 추력, 무게 및 밀도 보정}

(Thrust, Weight, and Density Correction)

이륙 비행 중 대기조건의 변화는 엔진의 이용 출력 (available power)을 변화시키게 되며, 표준 무게조건에서 표준 양력계수로 비행하기 위해 요 구되는 이륙속도를 변화시키게 된다. 이와 같은 효과를 매우 정확하게 보정하기 위해서는 복잡한 식이 요구되므로, 일반적으로 다음과 같은 경험 식을 지상이륙활주거리 및 공중 이륙거리 보정에 각각 사용한다.

$$
\begin{aligned}
& S_{1_{\text {std }}}=S_{1_{\text {texd }}}\left(\frac{W_{\text {std }}}{W_{\text {test }}}\right)^{2.6}\left(\frac{\sigma_{\text {test }}}{\sigma_{\text {std }}}\right)^{1.9}\left(\frac{N_{\text {test }}}{N_{\text {std }}}\right)^{0.7}\left(\frac{P_{a_{\text {tad }}}}{P_{a_{\text {std }}}}\right)^{0.5} \\
& S_{2_{\text {std }}}=S_{2_{\text {texd }}}\left(\frac{W_{\text {std }}}{W_{\text {test }}}\right)^{2.6}\left(\frac{\sigma_{\text {test }}}{\sigma_{\text {std }}}\right)^{1.9}\left(\frac{N_{\text {test }}}{N_{\text {std }}}\right)^{0.8}\left(\frac{P_{a_{\text {test }}}}{P_{a_{\text {std }}}}\right)^{0.6}
\end{aligned}
$$

\section{2 착륙비행단계 구분 및 보정식}

그림 4 와 같이 착륙비행단계 역시 이륙비행단 계와 마찬가지로 $50 \mathrm{ft}$ 장애물 고도에서 지면 활 주로에 touchdown할 때까지의 공중 착륙거리 (landing air phase distance, $S_{3}$ )와 touchdown 후 완전히 정지할 때까지의 착륙활주거리 $\left(S_{4}\right)$ 로 구분된다. 각각의 착륙거리는 식 (1)과 (2)와 유 사한 에너지 보존법칙을 사용하여 식 (11)과 (12) 로 유도할 수 있다.

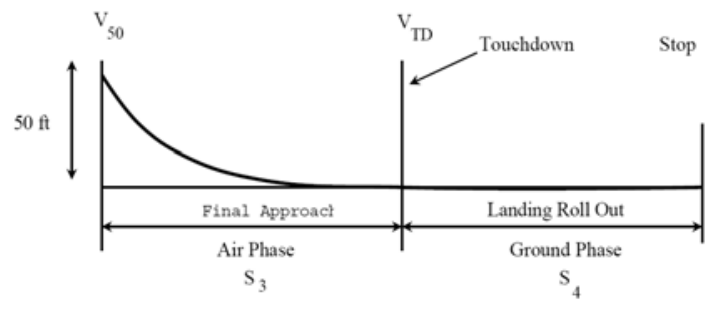

Fig. 3. Landing Phase 


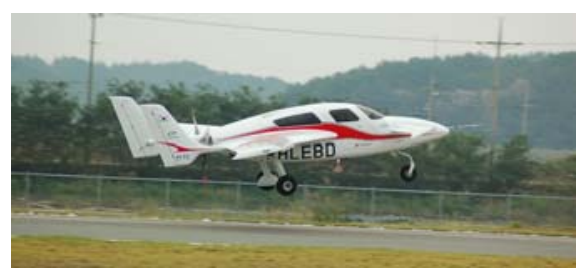

Fig. 4. Test-bed aircraft (Firefly \#3)

$$
\begin{aligned}
& S_{3}=\frac{W \cdot\left(\frac{V_{T O}^{2}-V_{A P_{\text {s0 }}}^{2}}{2 g}-50\right)}{(T-D)_{A v g}} \\
& S_{4}=\frac{-W \cdot V_{T D}^{2}}{2 g \cdot[T-D-\mu \cdot(W-L)]_{A v g}}
\end{aligned}
$$

착륙거리 보정식은 이륙거리 보정식과 동일하게 적용할 수 있으며, 식 (6)과 (8)의 $S_{1}, V_{L O F_{g}}$ 를 착 륙활주거리 $S_{4}$ 와 접지속도 $V_{T D_{q}}$ 로 대체하여 바람 속도와 활주로 기울기의 영향을 보정한다. 추력, 무게 및 밀도에 대한 보정은 다음과 같이 경험식 을 적용한다[4].

$$
\begin{aligned}
& S_{3_{\text {stl }}}=S_{3_{\text {test }}} \cdot\left(\frac{W_{\text {std }}}{W_{\text {test }}}\right)^{\left(2+\frac{E_{h}}{E_{h}+50}\right)} \cdot\left(\frac{\sigma_{\text {test }}}{\sigma_{\text {std }}}\right)^{\left(\frac{E_{h}}{E_{h}+50}\right)} \\
& S_{4_{\text {stt }}}=S_{4_{\text {tat }}} \cdot\left(\frac{W_{\text {std }}}{W_{\text {test }}}\right)^{2} \cdot\left(\frac{\sigma_{\text {test }}}{\sigma_{\text {std }}}\right)
\end{aligned}
$$

여기서, $E_{h}=\frac{V_{A P_{s 0}}^{2}-V_{T D}^{2}}{2 g}, P_{a_{s t t}}=P_{0}, \sigma_{s t d}=1$ 이다.

\section{Test-bed 항공기 및 비행시험 시스템}

\subsection{Test-bed 항공기 및 비행시험시스템}

본 논문의 비행시험 대상 항공기는 항공우주 연구원에서 개발한 4 인승 선미익형 항공기인 반 디 3호기 (Firefly \#3)이며, 비행시험은 한서대학 교 태안비행장에서 수행되었다. 반디호의 실속속 도는 $61 \mathrm{kts}$, 최대이륙중량은 $2,850 \mathrm{lb}$ 로 특히 착 륙시 $25 \mathrm{kts}$ 이상의 측풍에 대해서도 우수한 가 로안정성능을 보유하고 있다.

비행시험을 수행하기 위한 탑재 및 지상 계측 시스템은 실시간 텔레메트리 (telemetry) 시스템 을 활용하여 운용되며, 통신 주파수는 $2.2 \mathrm{GHz}$ 의 S-band를 사용한다 [5]. 비행시험 중 각종 비 행 데이터를 측정하기 위해 test-boom, IMU, 조종 면 변위측정센서 및 GPS 등이 장착되며, 비행계
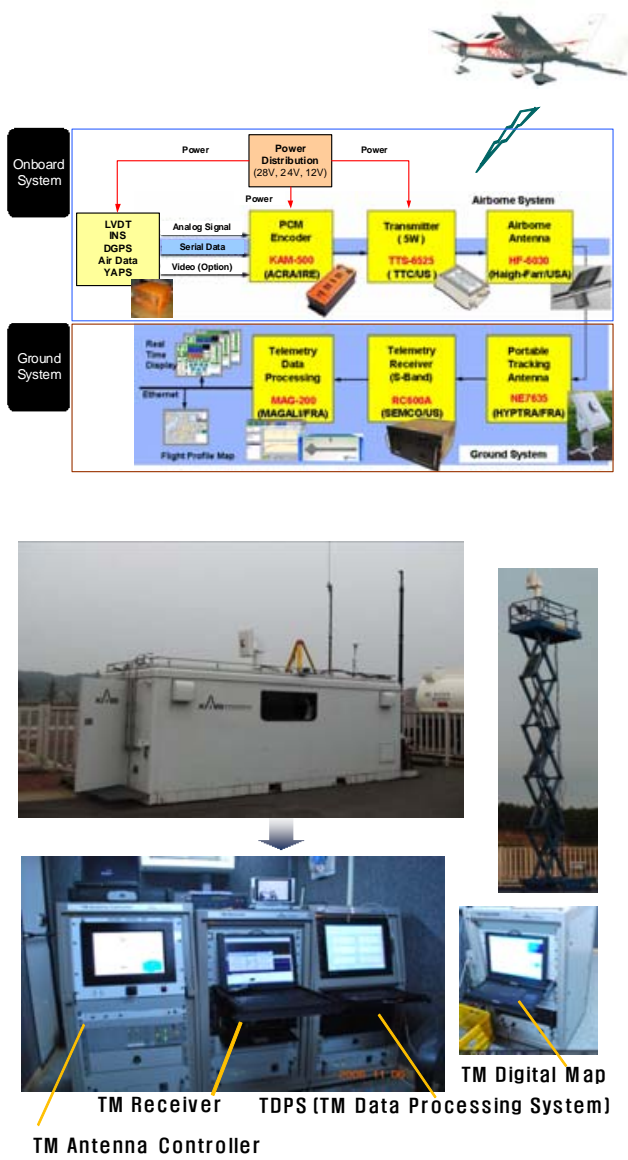

Fig. 5. Flight data acquisition system

측 센서로부터 측정된 각종 비행데이터는 지상으 로 전송되어 비행 중 비행상태 확인 뿐 아니라 추후 분석을 위해 저장된다[6]. Fig. 5는 구축된 텔레메트리 지상시스템을 보여주고 있다.

\section{$4.2 \mathrm{DGPS}$ 및 이착륙 거리 측정장치}

본 논문에서는 이착륙 거리 및 속도 측정데이 터의 정확도를 향상시키기 위해 레이저 거리 측 정장치와 DGPS를 적용하였다. 레이저 거리 측정 장치를 이용한 방법은 기존 지상관측법과 유사하 게 지상에서 관측자가 이륙 (또는 착륙) 중인 항 공기를 따라 측정하는 방식이며, DGPS 방식은 항공기에 지상 텔레메트리 시스템에 기준국을 설 치하고 보정신호를 항공기에 장착된 DGPS 수신 기에 송신하여 정밀위치를 측정하는 탑재방식으 로 적용하였다. 레이져 거리 측정장치는 호주 RIEGL사의 Lasertape FG1-HA로 최대 $600 \mathrm{~m}$ 까 지 $\pm 10 \mathrm{~cm}$ 의 정확도로 직선 거리 (LOS) 및 대상 체까지의 경사각 (inclination angle, $\eta$ )을 측정할 

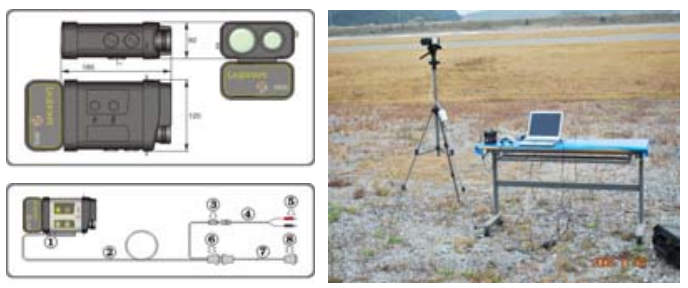

Fig. 6. Ground observation system using Lasertape(FG1-HA)
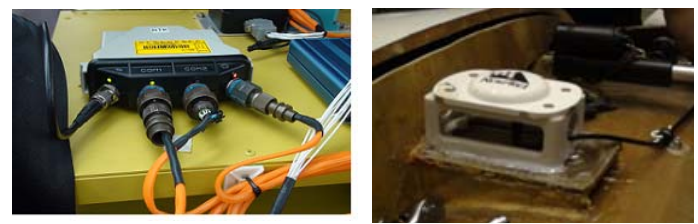

Fig. 7. DGPS receiver and antenna installed inside of test-bed aircraft

수 있으며, 수평방향 변위 각도 (horizontal angle, $\lambda$ ) 측정을 위해 포텐시오미터 (Midori사 CPP-45B)를 Fig. 6과 같이 삼각대 회전부에 추가 로 설치하였다. 측정데이터는 RS-232 통신을 통 해 노트북에 실시간으로 저장되도록 구성하였다. 본 연구에서 적용한 DGPS는 $20 \mathrm{~cm}$ 급의 오차 정 밀도를 가지는 RTK 시스템이며, 기준국은 Novatel사의 ProPak-V3 수신기를 이용하고 항공 기에는 Fig. 7과 같은 FlexPak-V2를 사용하여 보 다 정밀도 있는 비행시험 데이터를 확보하였다. DGPS 데이터는 $20 \mathrm{~Hz}$ 로 실시간 저장되며, 텔레 메트리 시스템을 통해 지상으로 전송된다. 속도 의 경우는 $0.03 \mathrm{~m} / \mathrm{s}$ 의 정확도를 제공한다.

\section{V. 비행시험 결과}

비행시험은 항시 위험성을 수반하기 때문에 사전에 철저한 준비와 비상시의 대응 방안 등을 사전에 수립하여야 하며, 시험항목에 대한 비행 시험 기준서, 비행시험 계획서 및 절차서와 비행 시험 데이터 카드 등 사전 준비문서 등을 작성하 고, 비행시험 후에는 비행시험 결과서를 작성하 게 된다.

\section{1 지상관측방법 적용 결과}

Fig. 8에 도시한 바와 같이 지상 측정 시스템 의 측정 데이터로부터 실제 이착륙거리는 식 (15)를 통해 구할 수 있으며, 저장된 시간정보를 이용하여 속도를 산출하게 된다.

$$
S=\sum_{i=0}^{k} S_{g i}=\sum_{i=0}^{k} \sqrt{a^{2}+b^{2}}
$$

here, $a=h_{d 1}-h_{d 2} \sin \left(\lambda_{2}-\lambda_{1}\right), b=h_{d 2} \cos \left(\lambda_{2}-\lambda_{1}\right)$

이륙비행시험에서 측정된 비행시험 데이터와 결 과를 Fig. 9에 나타내고, 착륙시험의 경우는 Fig.

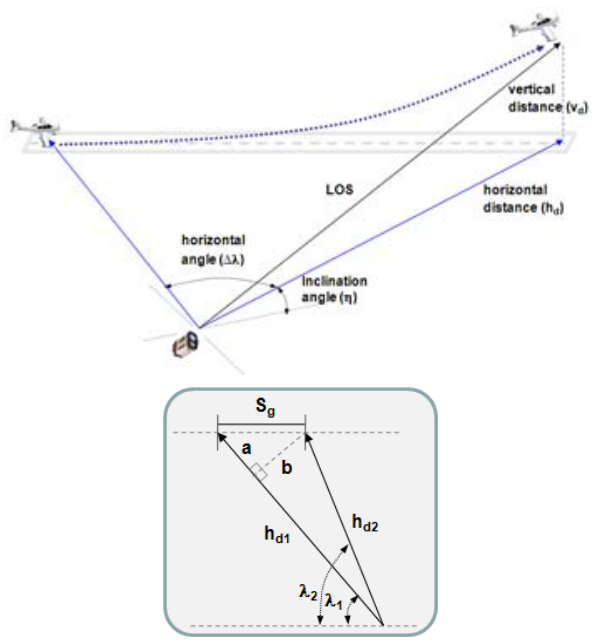

Fig. 8. Ground observation schematic
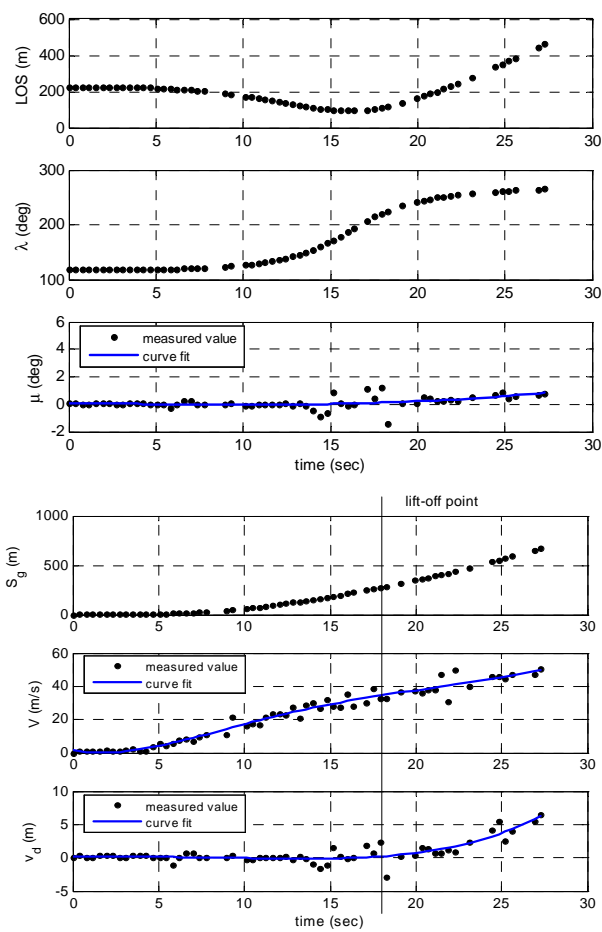

Fig. 9. Results for ground observation method(take-off) 

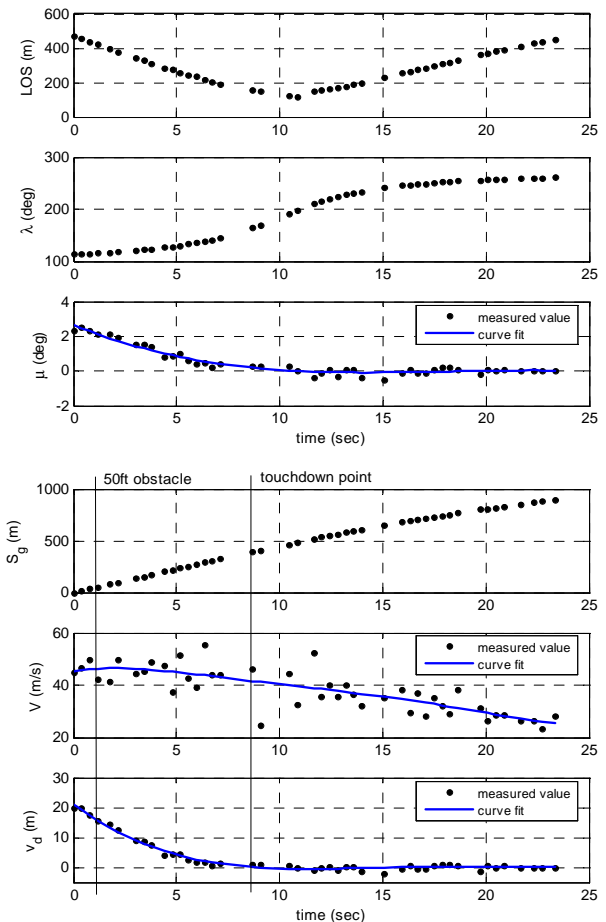

Fig. 10. Results for ground observation method(landing)

10 에 나타내었다. 측정값들 중 LOS 및 수평 각 도 $\lambda$ 는 정확하게 측정되었으나, 경사각 $\mu$ 는 분산 의 정도가 심한 편이었다. 이는 지상 관측자가 이륙하거나 착륙하는 항공기를 따라 레이저 거리 측정기로 정확히 조준하여야 하는 측정방법의 오 차이며, 수평방향에 비해 조준 정확도가 매우 민 감하게 영향을 받음을 확인할 수 있었다. 특히, 항공기가 지상 관측자의 바로 앞을 지나가는 구 간 (LOS가 최소값을 나타내는 구간)에서는 항공 기의 상대 속도가 매우 빠르기 때문에 분산정도 는 더욱 심해짐을 알 수 있다. 따라서, 경사각과 식 (15)를 통해 계산된 이착륙 거리는 curve fitting을 적용하여 성능값을 결정하였고, 사용한 레이져 거리계의 성능제한으로 인해 $600 \mathrm{~m}$ 이상 의 거리를 측정하지 못해 이륙시험의 경우는 지 상활주거리 $S_{1}$ 만을 대략적으로 결정할 수 있었 고, 착륙시험의 경우는 공중착륙거리 $S_{3}$ 만을 결 정할 수 있어 정확한 이착륙 거리를 산출 할 수 없었다.

\subsection{DGPS 방법 적용 결과}

GPS는 이미 항법 및 항행분야에서 주도적인 시스템으로 활용되어지고 있으며, 비행시험 분야
Table 2. Flight conditions

\begin{tabular}{|l|l|l|}
\hline \multicolumn{3}{|c|}{ TAKE-OFF \#1 } \\
\hline 날씨: 흐림 & 시정: $9 \mathrm{Km}$ & 운고: $16,000 \mathrm{ft}$ \\
\hline 풍속: $2 \mathrm{kts}$ & 풍향: $14^{\circ}$ & 온도: $15.7^{\circ} \mathrm{C}$ \\
\hline 압력: $30.072 \mathrm{inHg}$ & 습도: $68 \%$ & 무게: $2,793 \mathrm{lb}$ \\
\hline \multicolumn{3}{|c|}{ TAKE-OFF \#2 } \\
\hline 날씨: 흐림 & 시정: $8 \mathrm{Km}$ & 운고: $16,000 \mathrm{ft}$ \\
\hline 풍속: $4 \mathrm{kts}$ & 풍향: $18^{\circ}$ & 온도: $17.7^{\circ} \mathrm{C}$ \\
\hline 압력: $29.974 \mathrm{inHg}$ & 습도: $90 \%$ & 무게: $2,870 \mathrm{lb}$ \\
\hline \multicolumn{4}{|c|}{ LANDING \#1 } \\
\hline 날씨: 맑음 & 시정: $9 \mathrm{Km}$ & 운고: $25,000 \mathrm{ft}$ \\
\hline 풍속: $5 \mathrm{kts}$ & 풍향: $14^{\circ}$ & 온도: $14.2^{\circ} \mathrm{C}$ \\
\hline 압력: $30.095 \mathrm{inHg}$ & 습도: $75 \%$ & 무게: $2,805 \mathrm{lb}$ \\
\hline \multicolumn{4}{|c|}{ LANDING \#2 } \\
\hline 날씨: 맑음 & 시정: $9 \mathrm{Km}$ & 운고: $16,000 \mathrm{ft}$ \\
\hline 풍속: $6 \mathrm{kts}$ & 풍향: $16^{\circ}$ & 온도: $17.2^{\circ} \mathrm{C}$ \\
\hline 압력: $30.027 \mathrm{inHg}$ & 습도: $79 \%$ & 무게: $2,793 \mathrm{lb}$ \\
\hline
\end{tabular}

에서도 고전 기법을 대체하여 보다 정확한 비행 시험 결과를 제공할 수 있는 센서로 응용되고 있 다. 특히 정밀하고 유용한 위치정보 및 대지속도 를 제공하기 때문에 속도-고도 보정 시험에서 다 양한 방법으로 활용되고 있으며 [7][8], 본 논문 에서 다루고 있는 이륙 및 착륙 성능 결정에서도 타 측정 센서 및 시스템 보다 효율적이고 정확한 데이터를 제공함을 확인하였다.

DGPS 방법에 대한 비행시험은 이륙 및 착륙 시험에 대해 각 2회씩 총 4 회가 수행되었으며, 시험결과 해석에 필요한 시험당일의 기상조건 및 비행조건은 Table 2에 정리하였다.

획득한 비행시험 데이터의 분석과정은 저장된 전체 비행데이터 중 오류가 있는 데이터를 제거 한 후 이륙과 착륙시의 event 구간을 선정하고 해당구간에서의 이륙 및 착륙 성능을 해석하는 순서로 진행된다. 이륙 시험 데이터는 Fig. 11과 12에 나타내었다. event 구간의 선정은 비행데이 터 중 시험 엔지니어가 버튼을 눌러 기록한 event 정보와 DGPS 속도, 고도 자료 및 지상 텔 레메트리 시스템에 기록된 $\log$ 시간정보를 종합 적으로 판단하여 결정하였다. Fig. 11과 12에서 확인할 수 있는 것처럼 이륙을 위한 출발시점, 이륙 순간 및 장애물 고도 $50 \mathrm{ft}$ 도달시점은 DGPS 속도 및 고도값을 통해 정확히 결정할 수 있었으며, event 신호도 일치하게 발생했음을 확 인 할 수 있다. 첫 번째 이륙시험 데이터인 Fig. 11에서 출발부터 lift-off까지 ground phase는 약 18초, lift-off에서 $50 \mathrm{ft}$ 에 도달하기까지의 air phase는 약 11초가 소요되었다. 두 번째 이륙시 험 데이터에서는 각각 19.5초, 8.3초가 소요됨을 Fig. 12에서 확인할 수 있다. 


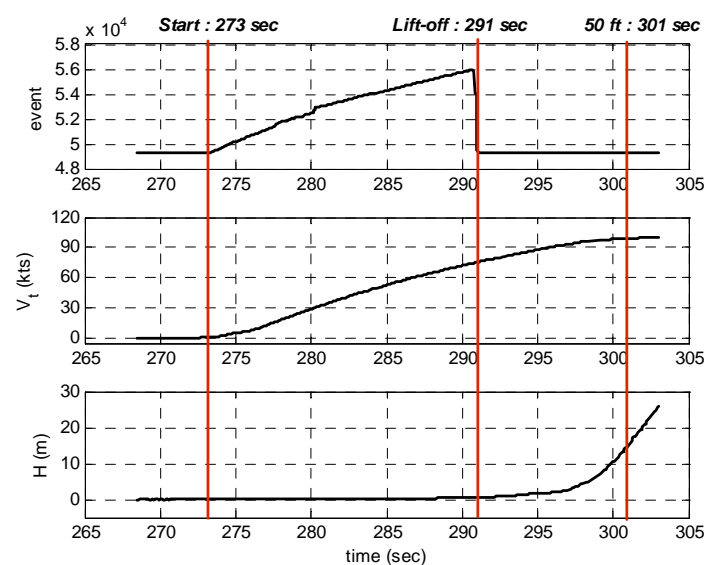

Fig. 11. Results of DGPS method(take-off\#1)

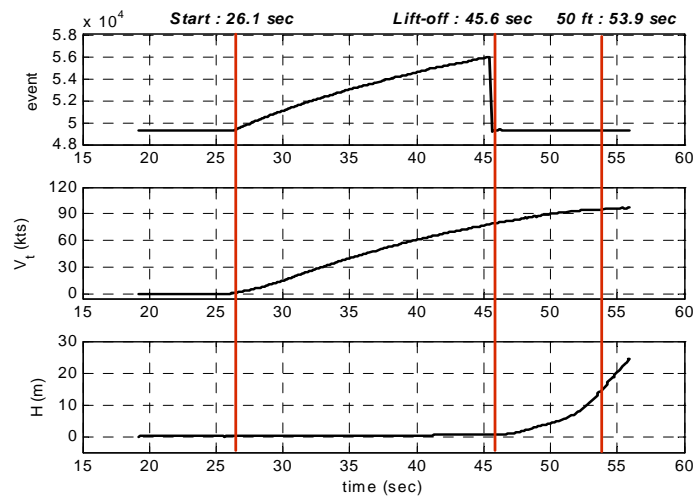

Fig. 12. Results of DGPS method(take-off\#2)

착륙성능 평가 역시 앞서 이륙평가 수행과 동 일하게 착륙 event 구간을 선정하고, 해석을 수 행하였으며, 착륙 비행시험 데이터는 Fig. 13과 14에 나타내었다. Fig. 13의 첫 번째 착륙시험의 경우는 장애물 고도 $50 \mathrm{ft}$ 상공에서 touchdown 까지의 air phase의 시간은 11.7초가 소요되었고, touchdown후 정지 할 때까지의 ground phase에 는 19.6 초가 소요되었다. 두 번째의 경우는 각각 15.8 초와 25.2 초가 소요되었다. 착륙시험의 경우 는 접근속도에서 착륙 후 정지할 때가지의 거리 를 결정하기 때문에 수초의 차이는 매우 큰 착륙 거리의 차이를 발생시키게 되므로, 이륙시험 보 다 보다 정교한 시험조종사의 조종이 수행되어야 한다. 이는 해석결과를 정리한 Table 3 에서도 확 인할 수 있으며, air phase 단계에서 발생한 비행 시간 4 초 차이는 착륙거리 결과에서 $551 \mathrm{ft}$ 의 차 이를 발생시킨다.
Table 3. Results of DGPS method

\begin{tabular}{|l|r|r|l|r|r|}
\hline \multicolumn{3}{|c|}{ TAKE-OFF } & \multicolumn{3}{c|}{ LANDING } \\
\hline & \multicolumn{1}{|c|}{$\# 1$} & \multicolumn{1}{|c|}{$\# 2$} & & \multicolumn{1}{c|}{$\# 1$} & \multicolumn{1}{|c|}{$\# 2$} \\
\hline$V_{L O F}$ & $76.9 \mathrm{kts}$ & $78.6 \mathrm{kts}$ & $V_{T D}$ & $66.3 \mathrm{kts}$ & $63.1 \mathrm{kts}$ \\
\hline$V_{T O_{50}}$ & $98.9 \mathrm{kts}$ & $95.2 \mathrm{kts}$ & $V_{A P_{s 0}}$ & $83.1 \mathrm{kts}$ & $84.2 \mathrm{kts}$ \\
\hline$S_{1}$ & $1,203.1 \mathrm{ft}$ & $1,383.7 \mathrm{ft}$ & $S_{3}$ & $1,280.4 \mathrm{ft}$ & $1,831.3 \mathrm{ft}$ \\
\hline$S_{1_{S I D}}$ & $1,214.6 \mathrm{ft}$ & $1,318.3 \mathrm{ft}$ & $S_{3_{S I D}}$ & $1,395.3 \mathrm{ft}$ & $2,008.2 \mathrm{ft}$ \\
\hline$S_{2}$ & $1,492.2 \mathrm{ft}$ & $1,256.6 \mathrm{ft}$ & $S_{4}$ & $1,230.3 \mathrm{ft}$ & $832.6 \mathrm{ft}$ \\
\hline$S_{2_{S I D}}$ & $1,468.9 \mathrm{ft}$ & $1,148.4 \mathrm{ft}$ & $S_{4_{S I D}}$ & $1,389.4 \mathrm{ft}$ & $969.8 \mathrm{ft}$ \\
\hline$S_{T O}$ & $2,683.5 \mathrm{ft}$ & $2,466.7 \mathrm{ft}$ & $S_{L}$ & $2,784.7 \mathrm{ft}$ & $2,978.0 \mathrm{ft}$ \\
\hline
\end{tabular}

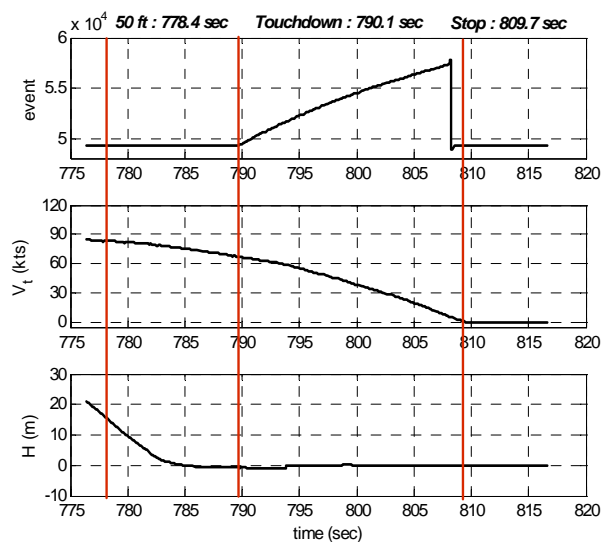

Fig. 13. Results of DGPS method(landing\#1)

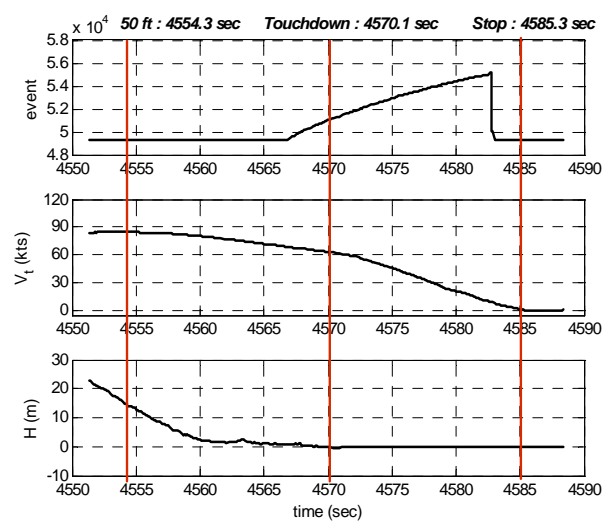

Fig. 14. Results of DGPS method(landing\#2)

그림 9와 10 에서 측정된 지상관측법은 Take-Off \#1과 Landing \#1의 조건에서 측정된 결과로 지상활주거리 $S_{1}$ 은 $943 \mathrm{ft}$ 로 DGPS 결과 와 약 $260 \mathrm{ft}$ 의 오차를 보였으며, 공중 착륙거리 $S_{3}$ 는 $1118.5 \mathrm{ft}$ 로 약 $162 \mathrm{ft}$ 의 오차를 나타내었다. 사용한 레이져 거리측정장치는 전문 비행시험 전 
용장비가 아닌 관계로 정확성의 한계가 있으며, 지상관측자의 측정오차가 크게 기인한 것으로 판 단된다.

이륙 및 착륙 시험 해석결과는 Table 2의 기상정 보를 바탕으로 이륙 및 착륙 시의 풍향과 온도, 압 력정보를 사용하여 표준조건으로 변환하며, 수차례 의 비행시험을 통해 평균값을 사용하여야 한다. 최 종적으로 이륙 및 착륙 성능 해석 결과는 감항기술 기준 $\$ 23.51$ 항의 $V_{L O F} \geq V_{S_{1}}, V_{50} \geq 1.2 V_{S_{1}}$ 및 $\$ 23.73$ 항의 $V_{A P_{50}} \geq 1.3 V_{S}$ 를 만족시키고 있으며, 접근 하강률 도 $2.5 \mathrm{deg}$ 로 $\$ 23.75$ 항의 하강률 규정 (하강률 < $5.2 \%(3 \mathrm{deg}))$ 을 만족시키고 있음을 확인하였다.

\section{VI. 결 론}

본 논문에서는 위치 정확도가 매우 우수한 DGPS 기법을 적용하여 이륙 및 착륙 성능 비행 시험을 수행하였다. 이착륙 비행시험의 경우, DGPS 방법은 $20 \mathrm{~Hz}$ 마다 측정되는 정확한 위치 및 속도 데이터를 통해 지상관측법에 비해 이륙 및 착륙 성능을 매우 정확하게 결정할 수 있으며, 특히 ground phase, air phase 및 장애물 고도 50 $\mathrm{ft}$ 까지도 세밀하게 분석이 가능한 장점을 제공한 다. 또한 지상의 관측자나 측정을 위한 장비들 불 필요하므로 비행시험의 효율성을 높일 수 있는 방 법으로 활용성이 매우 우수함을 확인하였다.

\section{후 기}

본 연구는 기초기술연구회에서 지원한 전문연 구사업의 결과이며, 시험조종을 맡아주신 한서대
학교 박수복 교수님과 아낌없는 지원을 해주신 홍교영 교수님께 감사드립니다.

\section{참고문헌}

1) "항공기 품질인증 기술기반 구축 사업 산업 기술기반조성에 관한 보고서“, 산업자원부, 2005.

2) "감항 분류가 보통 $(\mathrm{N})$, 실용 $(\mathrm{U})$, 곡기 $(\mathrm{A})$, 커 뮤터(C)류인 비행기에 대한 기술기준", KAS Part 23, 국토해양부, 2006.

3) 14 CFR Part 23, "Airworthiness Standards: Normal, Utility, Acrobatic, and Commuter Category Airplanes", FAA.

4) G. L. Gallagher, et al., "U.S NAVAL Test Pilot School Flight Test Manual - Fixed Wing Performance", USNTPS-FTM-No.108.

5) 김현경, 김태식, 장재원, 전향식, “반디호 비 행시험을 위한 텔레메트리 데이터 처리시스템", 항공우주학회 추계학술발표회, 2008, pp. 1266-1269.

6) 장재원, 이상종, 김현경, 전병호, 문상만, 성 기정, "소형 항공기용 비행시험 장치 개발", 항공 우주학회 춘계학술발표회, 2009, pp. 1017-1020.

7) 이상종, 박정호, 장재원, 박일경, 성기정, 김 병수, “DGPS를 이용한 소형항공기 속도-고도 보 정 비행시험 기법", 한국항행학회 학술발표회, 2008, pp. 335-339.

8) 박정호, 김병수, 이상종, 장재원, 성기정, “소형 항공기용 비행시험 장치 개발", 항공우주 학회 춘계학술발표회, 2009, pp. 574-579. 